\title{
EL AJEDREZ BORGIANO EN EL ÍNCIPIT SIETE DE SI UNA NOCHE DE INVIERNO UN VIAJERO, DE ITALO CALVINO
}

\author{
Juan Carlos Pino Correa \\ Universidad del Cauca \\ Popayán, Colombia \\ jcpino@unicauca.edu.co
}

\section{INTRODUCCIÓN}

Si un lector pasa un día frente al estante de su sala y ve un ajedrez de madera, además de pensar en unos versos de Borges es posible que piense en Italo Calvino. Y no sería descabellado que imaginara que, en Roma, cuando en el otoño de 1984 coincidieron en un evento del Ministero Della Pubblica Istruzione ${ }^{1}$, los dos escritores juegan una partida como pretexto para el silencio. Eso puede pensar el lector, invariablemente, después de haber leído Si una noche de invierno un viajero, una novela que le hizo regresar a los laberintos y a los espejos, a los apócrifos, a los sonetos borgianos. ¿Cómo no hacerlo en una narración fragmentaria que es un laberinto? ¿Cómo no hacerlo si en los relatos hay espejos y enigmas por resolver, hay autores que no lo son, o que pueden haberlo sido o lo serán? Y puede pensar el lector en esa posible partida cuando, en el capítulo siete, Ludmilla dice que le "gustan los libros en los que todos los misterios y las angustias pasan a través de una mente exacta y fría y sin sombras, como la de un jugador de ajedrez" (Calvino, Si una noche 168). ¿Cómo plantear entonces esa relación entre juego, escritura y lectura? ¿Cómo desentrañar las estructuras que rigen a estos mundos y

$1 \quad$ Gloria Galli de Ortega dice que la relación entre los dos escritores se dio más allá de los libros, pues compartían estrategias y temas, y que "fue Calvino quien lo recibió [a Borges] en 1984 en el Ministerio de Instrucción Pública en nombre del Gobierno y de la cultura italiana" (169). 
la relación misteriosa que hay entre ellos? Sí, es imposible no imaginar a Calvino y a Borges jugando silenciosos una extraña partida de ajedrez: un juego de espejos entre un lector, un escritor, un editor, un lector, un escritor y un bibliotecario. O todos ellos. Es el otoño de 1984. Un buen pretexto.

\section{LOS ESCAQUES, METÁFORA DEL MUNDO}

En Si una noche de invierno un viajero, el lector busca desesperadamente la continuación de unas novelas que le parecen inconclusas y que por errores tipográficos u otras confusiones ha debido interrumpir. Así, se encuentra con un libro titulado En una red de líneas que se intersecan, el último éxito de Silas Flannery, y lo primero que le extraña es que difiera en una palabra apenas del libro que hace poco había tenido que interrumpir: En una red de líneas que se entrelazan. Pero una novela no es la continuación de la otra, ni de las que vienen, e incluso puede pensarse que son plagios o reescrituras con autores apócrifos. Como dice Van Der Linde, refiriéndose específicamente a este juego de escritos apócrifos, "la implicación de la trama llevada a último término sería declarar la muerte del autor" (191). Ese es el destino, o el desafío, mejor, que el autor (Flannery, Calvino, o cualquier otro) le ha impuesto al lector: la búsqueda de un hilo de Ariadna para poder hallar la salida del laberinto, un hilo que puede ser una respuesta o puede ser muchas, sujeto tal vez al mundo hermenéutico del que lee. No obstante, todo esto puede ser una trampa, pues el propio Calvino confiesa que la relación lector-escritor puede estar regida por un cierto sadismo donde él (el escritor, Calvino) es el dueño de la situación y juega con el lector al gato y al ratón, “dejándolo disfrutar brevemente de la ilusión de que es libre por un tiempo, de que tiene el control"' (cit. en Du Plessix Gray párr. 17)².

Ese juego del gato y el ratón puede ser una partida de ajedrez acaso desigual, donde el lector juega a ciegas confiando solo en las coordenadas que el autor le da. Pero, al igual que en una verdadera partida a ciegas, también es posible en la mente visualizar el tablero y ubicar las piezas y los movimientos, extasiarse en el paisaje, como en Novela de ajedrez (1943), de Stefan Zweig. Y vislumbrar en la aparente oscuridad las bifurcaciones que se pueden suceder: "El diálogo hermenéutico queda planteado en términos 
de un ocultamiento por parte de la escritura, es decir de la obra, y por un desvelar por parte del espectador" (Van Der Linde 190).

En aquel séptimo íncipit titulado En una red de líneas que se intersecan, el autor empieza proponiendo el siguiente escenario:

Especular, reflejar: toda actividad del pensamiento me remite a los espejos. Según Plotino el alma es un espejo que crea las cosas materiales reflejando las ideas de la razón superior. Será quizá por eso que yo para pensar necesito espejos: no sé concentrarme más que en presencia de imágenes reflejas, como si mi alma necesitase un modelo que imitar cada vez que quiere poner en práctica su virtud especulativa (Calvino, Si una noche 173).

Podría llegar a pensarse, aquí, que el ajedrez, como juego con su tablero y sus trebejos, llega a ser un universo donde el autor-jugador ve reflejadas sus ideas y sus pensamientos, y, por tanto, su alma. Este planteamiento tiene mucho de borgiano -herencia, por supuesto, de Plotino, "sombra también"sobre todo cuando el escritor argentino se pregunta, en el poema titulado "Beppo”, “¿De qué Adán anterior al paraíso, / de qué divinidad indescifrable / somos los hombres un espejo roto?" (Borges 295).

¿Dónde puede verse reflejado el autor de En una red de líneas que se intersecan si de verdad estuviera jugando al ajedrez? ¿Y dónde su lector? Habría que intentar algunas respuestas. Todos pueden verse reflejados en el tablero, que es como el escenario marco y, si se quiere, el objeto visivo que termina convirtiéndose en un mapa, en una red, en una coordenada, tal como lo plantea Marco Belpoliti, cuando dice que Calvino "había individualizado la imagen-metáfora de la red siguiendo la teoría de los sistemas. El mismo mapa se basa en una retícula de coordenadas" (42). Belpoliti llama la atención sobre un planteamiento similar de Calvino en Las ciudades invisibles, cuando el relato de Marco Polo sobre sus viajes se inserta en esa red que es el tablero de ajedrez erigido en el diálogo-intercambio que este sostiene con Kublai Kan. Eso explica que el Gran Kan espere al veneciano delante del tablero al volver de su última travesía y lo invite con un gesto a sentarse frente a él "y a describirle con la sola ayuda del juego las ciudades que había visitado" (Calvino, Las ciudades 132). En ese mismo sentido, Fernando Aínsa señala que esas ciudades que Marco Polo "le describe con abundancia de detalles son representadas con una u otra disposición de torres, alfiles, caballos, reyes, reinas, peones, en sus casillas blancas y negras" (80). 
En ese universo de coordenadas claramente establecidas, el tablero conoce todas las historias pasadas, presentes y futuras, por haber sido testigo de las combinaciones hechas en sus sesenta y cuatro escaques y por imaginar las aún no realizadas pero posibles: las jugadas de cualquier niño inquieto en un pueblo olvidado o las jugadas hechas en la partida 24 de Sevilla en 1987 por el Campeonato Mundial de Ajedrez cuando Garry Kasparov derrotó magistralmente a Anatoli Karpov, para poner tan solo dos ejemplos ${ }^{3}$. Cualquier movimiento en cualquier lugar del mundo. Unos movimientos como reflejo de otros, unas historias que empiezan de manera similar y que después se ramifican infinitamente, habiendo tenido antes la posibilidad de tomar otros senderos que también en cada paso podrían haberse ramificado hasta el infinito ${ }^{4}$. Ya decía Poe en el siglo XIX, analizando al jugador de ajedrez de Maelzel, que no hay en este juego una progresión determinada y no hay continuidad necesaria entre un movimiento y otro porque "a medida que se avanza en la partida avanza asimismo la incertidumbre de cada movimiento siguiente" (88).

En ese contexto, aquellos escaques o cuadros blancos y negros son el mundo, el lugar donde se concretan las ansias, los deseos y las ilusiones, con tanta fuerza como los odios, las maldades y las mezquindades. Ese tablero puede ser considerado de algún modo el único espejo del que habla el narrador de este libro séptimo de Si una noche de invierno un viajero, donde todos los mundos y los universos y las cosas están presentes:

De espejo en espejo - eso es lo que a veces sueño- la totalidad de las cosas, el universo entero, la sabiduría divina podrían concentrar sus rayos luminosos en un único espejo. O quizá el conocimiento del todo esté sepultado en el alma y un sistema de espejos que multiplicase mi

\footnotetext{
Puede mencionarse que, en la llamada Guerra Fría, época de grandes tensiones ideológicas entre Estados Unidos y la Unión Soviética, el ajedrez, como una expresión de la confrontación, tuvo un papel muy importante y el culmen fue el match entre el estadounidense Bobby Fischer y el soviético Boris Spassky llevado a cabo en Reikiavik, Islandia, en 1972. Dice Eric Hobsbawm que en ese lapso donde las dos grandes potencias se mostraban dispuestas permanentemente a entrar en combate, "generaciones enteras crecieron bajo la amenaza de un conflicto nuclear que, tal como creían muchos, podía estallar en cualquier momento y arrasar a la humanidad" (230).

Bien podría pensarse, aquí, en la figura del Aleph, ese punto del espacio que contiene todos los puntos, "el lugar donde están, sin confundirse, todos los lugares del orbe, vistos desde todos los ángulos" (Borges, El Aleph 623).
} 
imagen al infinito y restituyese su esencia en una única imagen me revelaría el alma del todo que se esconde en la mía (177).

El tablero puede contener esa "única imagen" que refleje el alma del todo buscada por quien narra y por eso no es casual que intente consolidarse como esa "mente exacta y fría y sin sombras" (Calvino, Si una noche 168) de un jugador de ajedrez. Aunque asimismo cabe preguntarse si Ludmilla, al referirse a esa mente a través de la cual pasan "todos los misterios y las angustias" (ibid.), está señalando al narrador. Porque igual puede ser un guiño al lector e, incluso, al autor. O mejor sería que todos tuvieran esa lucidez en el momento del encuentro. No en vano, en el prólogo a la primera edición de Historia universal de la infamia, Borges señala que "a veces pienso que los buenos lectores son cisnes aun más tenebrosos y singulares que los buenos autores" (289).

El autor puede verse reflejado, además, en los trebejos (en todos y en cada uno), en sus vivencias trágicas o benevolentes, desesperadas o victoriosas, tristes o esperanzadoras, en los movimientos que lo estremecen, en algún recuerdo o en cierta insondable premonición. A veces se verá cabalgando el corcel veloz y arrogante en un ataque implacable, o a veces replegado en un peón que hace muralla con otros defendiendo a su rey y que más tarde será coronado en pos del triunfo. Pero también puede ser un aguerrido y arriesgado alfil, que en cualquier momento se torne en kamikaze, o puede ser una "torre homérica" (Borges, "Ajedrez" 813), a veces derribada y a veces impetuosa, que resguarda desde una esquina los tesoros del reino o avanza impertérrita en busca de nuevas tierras, antes o después de un enroque. Y puede ser la dama fuerte y ágil, sensible, elegante, cruel en ocasiones, o puede ser el rey destinado a la derrota. Aquí se intentará la proyección de un solo ser que a la vez sea todos los seres. O la de un libro que es a la vez todos los libros: "Los libros están hechos para ser en otros, un libro único tiene sentido solo en cuanto se une a otros libros, en cuanto continúa y precede a otros libros" (Calvino, "El libro" 16). Haciendo la trasposición al ajedrez, ¿cómo no pensar que el peón no solo es él mismo sino, al mismo tiempo, es el rey que defiende o es la dama que idolatra? Y viceversa. En ese sentido, Borges recuerda que un heresiarca de Tlön conjetura que "hay un solo sujeto, que ese sujeto indivisible es cada uno de los seres del universo y que estos son los órganos y máscaras de la divinidad" (438).

Pero existe otra posibilidad de reflejo. La que se da en la historia misma construida no con cada movimiento en particular ni con la mera sumatoria 
de todos sino con la eclosión del espíritu del juego y que es, en definitiva, la proyección de todo un universo. Ese universo que se hace bello como una flor de primavera y que puede expresar en una situación silenciosa el alma de un hombre, sus características esenciales. Como lo hace la literatura a través de un poema o un relato, que tampoco son la mera juntura de letras ni la sumatoria sin más de palabras. Es el alma que trasciende y toca a los demás, con su sencillez o su complejidad, con su concreción o su abstracción, o, como plantea un personaje de Novela de ajedrez, de Stefan Zweig, con su perennidad y perpetuo desarrollo, aun ante su esterilidad por considerarse "un pensamiento que no lleva a nada, una matemática que nada calcula, un arte sin obras, una arquitectura sin sustancias" (18).

Es en este sentido en el que el autor ha estructurado su íncipit siete de Si una noche de invierno un viajero entre las menciones al ajedrez y a los espejos, que equivaldría a decir: entre la infinitud y la incertidumbre, entre la proyección y el reconocimiento, entre el juego y el reflejo, entre la visión de los otros como un todo pero también como un yo que se mira incesantemente, entre las coordenadas y los espacios, entre la alegría y los miedos, entre los escaques y las lunas, entre la fantasía y la aparente realidad, entre la partida que es pero que puede haber sido y será y el hombre que es pero ha sido y será, entre la angustia de la condición humana ante la individualidad y el anhelo-temor ante la multiplicidad. Ahí podría entenderse al narrador de En una red de líneas que se intersecan cuando dice que quiere multiplicar su imagen "pero no por narcisismo o megalomanía como podría creerse con demasiada facilidad: al contrario, para esconder, entre tantos fantasmas ilusorios de mí mismo, el verdadero yo que los hace moverse" (Calvino, Si una noche 174).

Pero ¿quién mueve a quién? ¿Son los reflejos los que se mueven porque un ser real de carne y hueso se movió antes? (Esto es un decir, por supuesto. No hay un ser de carne y hueso aquí sino un ser gramatical, alguien hecho de palabras que se nos parece de manera irrefutable a un ser de carne y hueso: otro espejo, sin duda). ¿O es posible que uno de los reflejos, como sosias libertarios, se mueva una milésima de segundo antes de que se mueva el ser de carne y hueso y repita su movimiento? Acaso sea el retorno al juego del gato y el ratón al que se refiere Calvino, pero no como al principio sino previsto ahora en otras variantes. El juego del gato y el ratón en el que están inmersos no solo unos personajes con otros sino también los personajes con el narrador y el narrador con el autor (real o apócrifo), de la misma forma como las fichas del ajedrez lo están con el jugador que gobierna su destino. ¿Y después con 
quién? Borges plantea en los dos tercetos de su segundo soneto sobre el ajedrez una pregunta que, indudablemente, pasa por reflexiones metafísicas:

También el jugador es prisionero

(la sentencia es de Omar) de otro tablero

de negras noches y de blancos días.

Dios mueve al jugador, y éste la pieza.

¿Qué dios detrás de Dios la trama empieza

de polvo y tiempo y sueño y agonías? (“Ajedrez” 813).

En relación con este último terceto, László Scholz dice que, en esta metáfora del ajedrez, como una expresión de humildad y consolación, Borges muestra la ignorancia del destino que tienen tanto piezas como jugadores y que, en vez de "abandonarnos" en un mundo vaciado del saber, el autor argentino vislumbra "un sentimiento secreto, lo de la conciencia del no-saber, del ser insignificantes" (56).

\section{ENTRE LO DIONISÍACO Y LO APOLÍNEO}

En esa trama de polvo y tiempos y agonías, en esa trama de ignorancias y desconocimientos, en esa trama de partidas ciertas o imaginadas, en esa trama de juegos individuales y en esa trama de espejos es donde Calvino plantea la idea de la escritura como creación y visualización de mundos que se hacen y rehacen-como "ciudades invisibles", potenciales, en las cuales transcurre la acción-y donde se concreta la articulación de la quietud con el movimiento y la luz, que son acaso la encarnación del vivir en múltiples espacios y tiempos, es decir, en una red con muchas líneas que se intersecan. Así, el narrador del íncipit siete, frío y calculador como un ajedrecista, manifiesta que "estas páginas que estoy escribiendo deberían también transmitir una fría luminosidad de galería de espejos, donde un número limitado de figuras se refracta y se invierte y se multiplica" (Calvino, Si una noche 174-175). Pero, para lograrlo, es absolutamente indispensable tener todo muy bien elaborado y planeado, porque se está en el punto en que el escenario planteado es "una partida difícil, en la cual todo error podía pagarse muy caro" (Calvino, Si una noche 178). Por eso se insiste en tener racionalizada hasta la perfección esta red de espejos que es, además, un laberinto y una cárcel luminosa y colorida. 
María J. Calvo Montoro se refiere, en un ensayo sobre Umberto Eco, que a esta obra de Calvino le viene bien la necesidad de construcción de nuevos códigos, de verdaderas redes de piedra para cada estructura: "Aunque sea para crear la confusión de los laberintos de la escritura, o su contrario, las instrucciones para salir de ellos, lo evidente es que toda arquitectura necesita una sintaxis" (257).

Esa planificación y esa visualización nos remiten a las palabras del propio Calvino al calificar su íncipit siete como una novela lógico-geométrica, con todo lo que estos términos significan, considerados tanto individualmente como unidos por un guion, y que señala como "un ejemplo de narración que tiende a construirse como una operación lógica o una figura geométrica o una partida de ajedrez" (Si una noche 11). Además, menciona a dos autores que enfocan su modo de contar en esa perspectiva: Borges y Poe. Lucía Gregori recuerda que Calvino tuvo una gran influencia en París por parte del OuLiPo (Ouvroir de Littérature Potentielle), para el cual no había que pensar el arte en términos de epifanía casual ni de efusión espontánea sino "el simple desarrollarse, casi el 'despliegue' material de papel comprimido, apelotonado; comprimido pero organizado previamente, hecho de 'certezas' con forma matemático racional" (51).

En ese contexto, los códigos y las estructuras de un texto-llámese íncipit, pequeña novela, comienzo inconcluso, palimpsesto o texto fragmentario-no pueden tener fisuras y deben estar relacionados no solo con su propia historia sino con el todo en el cual están inmersos, así como tener articulación con los demás referentes intertextuales, en los términos en que lo plantean Kristeva y Genette ${ }^{5}$. Gian Paolo Biasin advierte esto con claridad al afirmar que

la multiplicación, y por consiguiente el principio combinatorio, no se refiere solo a la situación o a la trama, sino que se repite y amplía a un nivel más abstracto y sutil: el de la construcción y la estructura narrativa, ya que el conjunto de novelas insertas en Se una notte d'inverno un viaggiatore, cada una de ellas narrada en primera persona, constituye “un 'campo' nel quale una molteplicità di io dice

\footnotetext{
"Todo texto se construye como un mosaico de citas, todo texto es absorción y transformación de otro texto", afirma Kristeva (190), quien en la década de los sesenta dio origen al término "intertextualidad" a partir del concepto de "dialogicidad", instaurado por Mijaíl Bajtín. La narratología de Gérard Genette surge por desarrollos y reflexiones posteriores de este concepto.
} 
o suggerisce una serie di visioni su una molteplicitá di mondi”, como ha observado Cesare Segre (23).

Aparecen entonces en el horizonte nuevas proyecciones y desdoblamientos, nuevas bifurcaciones por imaginar y caminos por recorrer, controlados todos por una mente exacta y fría, la mente de un ajedrecista que, en esencia, será (o deberá ser, aunque aquí pareciera paradójico) apolínea, en el sentido nietzscheano: "Apolo, en cuanto Dios de todas las fuerzas figurativas, es a la vez un dios vaticinador" (Nietzsche 62). Esto ocasiona, según algunos críticos, un cierto distanciamiento ante el lector. Así lo recuerda Beno Weiss, al señalar que, para Nietzsche, Apolo, el dios de la paz, está asociado con el ocio, el descanso, y además con las emociones estéticas y la contemplación intelectual (127). Se le conoce además por ser el dios del orden lógico y de la serenidad filosófica; lo apolíneo es la base de todas las distinciones analíticas. Todo lo que tienen de único un ser humano o una cosa es apolíneo. Las formas y las estructuras son todas apolíneas, ya que la forma es lo que define o individualiza lo formado. También es apolíneo el pensamiento racional porque está estructurado y hace distinciones. En esa esfera de racionalidad, predomina lo geométrico, lo estático, lo formal. Calvino manifiesta, pues, muchos rasgos apolíneos y "literaturiza" la vida (ibid.).

La novela lógico-geométrica titulada En una red de líneas que se intersecan será, entonces, una novela apolínea en sí misma, por sus rasgos y características, pero lo será de igual modo en relación con todo el entramado ajedrecístico de Si una noche de invierno un viajero, con todo aquel mundo catóptrico, caleidoscópico, apócrifo, especular, que ha creado Calvino. Por eso, hablando precisamente de este libro, el autor italiano confiesa que los escritores de novelas quieren "tejer una red que ligue la experiencia guardada en los libros durante siglos con esa dispersión de experiencias que encontramos día con día en nuestras vidas y que nos resulta siempre más inasible e indefinible" ( $\mathrm{Si}$ una noche 18). No podría dudarse de ello si al final del íncipit siete el narrador se halla atrapado en su propio laberinto por un aparente "error" en su juego, como si este se le hubiera salido de las manos, o como si Dionisio hubiera entrado también en el juego con su espíritu desenfadado y travieso. ¿Podría pensarse, entonces, que en esta novela alguien cumple una doble función de jugador-narrador o, por el contrario, el narrador cumple apenas ese rol y no es el verdadero jugador que pudiera llegar a sugerirse? El jugador, prisionero también de otro tablero, como dice Borges (“Ajedrez" 813), se sabe ahora víctima de su propio invento de reflejos y de maquinaciones y no necesariamente porque 
hubiera sido raptado por él mismo o por ser la proyección del Señor de las Tinieblas, como lo temió en un principio. Él era el ratón. Había otro jugador, o mejor, una jugadora silenciosa, paciente y más hábil que lo atrapó en las redes que el narrador mismo construyó. En términos de imagen ajedrecística, el narrador sería el rey derrotado por su propia dama, quien en una trampa bien urdida atrajo hasta su territorio a la dama enemiga, la de otro color, para que fuera testigo de la catástrofe y de la inédita traición en aquella vorágine de dimensiones propuestas que se funden y se confunden. Quizá sea importante traer a colación a Tea Stoka cuando plantea que Borges trata el tiempo como si fuera el espacio y eso es una particularidad revolucionaria: "En vez de tener en cuenta la calidad unidireccional del tiempo, su rigurosa lógica de causa y consecuencia, él le da la vuelta al tiempo, lo bifurca, ramifica y duplica" (85). En esta novela, Calvino hace hago similar.

Pero, ¿es apolíneo el que todos se hayan perdido? ¿O es una trampa más del autor con el lector? ¿Otra vez alguien tira de la alfombra? El escenario, pues, insinúa el caos en el que no se encontrará el hilo de Ariadna y donde las imágenes se repetirán infinitamente en el tiempo y en el espacio. Hay una frase final que resume la esencia de lo planteado: "Ahora, me parece que todo lo que me circunda es una parte de mí, que he logrado convertirme en el todo, finalmente..." (Calvino, Si una noche 179). En definitiva, la estructura de la narración es apolínea, pero el mundo narrado parece deliberada y paradójicamente dionisíaco.

\section{PUZZLE DE UNIVERSOS}

Para la ciencia de la hermenéutica, la lectura es interpretación, es construcción de sentidos y no una simple traducción de signos: "La recepción de una obra literaria a través del oído interior que escucha en la lectura es un movimiento circular en el que las respuestas se tornan preguntas y provocan nuevas respuestas" (Gadamer 15). Lectura y recepción son entendidas aquí en un sentido muy amplio, en todas las formas imaginadas y posibles, en todos los objetos, en todos los ambientes, en todos los horizontes, en todos los lenguajes, en todos los paisajes. De Calvino se podría tomar un fragmento, a manera de ejemplo:

La lectura que los amantes hacen de los cuerpos (de ese concentrado de mente y cuerpo de que los amantes se sirven para ir a la cama 
juntos) difiere de la lectura de las páginas escritas en que no es lineal [...] El aspecto en el cual el abrazo y la lectura se asemejan más es que en su interior se abren tiempos y espacios distintos del tiempo y el espacio mensurables (Si una noche 167).

Esos tiempos y espacios no mensurables en que conviven el abrazo y la lectura (los dos pueden ser uno si de libros se trata) es el escenario donde el lector debe moverse con soltura y agilidad, pero con una actitud irrefrenable y decidida, con una mirada despierta y crítica para poder encontrar los significados y símbolos no solo en las palabras sino en lo no dicho, en lo sugerido, en lo evocado, en lo oculto, en lo apenas esbozado, en lo silencioso, en el espacio blanco entre unos caracteres y otros, entre una línea y otra, entre un párrafo y otro. $\mathrm{Y}$ en lo hipertextual ${ }^{6}$, en lo enigmático, en lo misterioso, en lo abstracto, en lo sentimental, en lo doloroso. Siempre lejos de cualquier intromisión que pueda desconcentrarlo. Esfumado en lo indistinto el mundo de alrededor, como dice Calvino (Si una noche 23). Ese es el camino que el lector debe seguir con cualquier libro que decida enfrentar. Y aquel reto se hace más complejo si la historia tiene apócrifos y espejos y laberintos, como el íncipit que aquí se analiza, donde el lector y la lectora (Ludmilla) buscan a través de sus lecturas paralelas armar el puzzle que el autor les ha propuesto, asumiendo con entereza, como dice Rocco Capozzi, su competencia "no para colaborar en la génesis del texto sino para reconocer los 'significados inesperados' y los 'fantasmas escondidos' del escritor y de la sociedad” (79). Así, un lector o una lectora es lo que el autor sueña como su ideal, llámese Ludmilla o de cualquier otra manera, porque lo que interesa es, justamente, su actitud, que no es una sola sino que pueden ser muchas, tal como Calvino lo plantea al final de la novela: el que busca universos, el que hace nuevos descubrimientos, el que penetra en el espíritu del texto, el que en cada libro está leyendo su único libro total y unitario que es la suma de sus lecturas, el que quiere recuperar el libro leído en la infancia, el que activa su imaginación con la promesa de la lectura, el que navega más allá del fin (Si una noche 263-264) -“cuando los jugadores se hayan ido / cuando el tiempo los haya consumido / ciertamente no habrá cesado el rito", dice Borges (“Ajedrez" 813)-, el que es exegético pero relaciona la unidad con el todo y lee invariablemente

${ }_{6}$ En Palimpsestos, la literatura en segundo grado, Gérard Genette define el hipertexto como "todo texto derivado de un texto anterior por transformación simple (diremos en adelante transformación sin más) o por transformación indirecta, diremos imitación" (17). 
desde el principio hasta el fin. En tal sentido, María J. Calvo insiste en que, en Si una noche de invierno un viajero, Ludmilla no solo es una ferviente lectora sino que defiende la lectura por placer, reflexiona sobre la escritura y se constituye para Calvino en una voz privilegiada: "Ludmilla es, en definitiva, el punto de interés en el que coinciden las miradas de los demás personajes, tanto de dentro de la 'cornice' como de los relatos interpuestos" (Calvo, El problema 260).

Así las cosas, puede decirse que los lectores son infinitos, autoconstruidos y construidos como reflejo del libro, pero también como proyección de su propia vida, por un lado, y de la sociedad toda, por el otro. Por eso muchas historias esperan siempre y es vital ir a por ellas, LEERLAS, así, con mayúsculas. Porque, como dice Borges: "Leer, por lo pronto, es una actividad posterior a la de escribir: más resignada, más civil, más intelectual" ("Prólogo" 289). Y como dice Calvino: Si una noche de invierno un viajero es "una novela sobre el placer de leer novelas" ("El libro" 20).

¿Cómo evitar imaginar, a partir de lo aquí planteado, una escena o un relato donde Calvino y Borges juegan silenciosos una extraña partida de ajedrez en el Ministero Della Pubblica Istruzione, en el otoño de 1984? Aquello podría haber ocurrido con unos pocos y privilegiados espectadores como testigos. Incluso podría suceder que, un día, un lector lo asumiera como el verosímil eje ficcional de un relato, con los escaques, los libros y los apócrifos como telón de fondo:

El dieciséis de octubre de 1984, en una tarde aún tibia de la Ciudad Eterna, el editor y el bibliotecario, cómplices en el pretexto de convocar otra forma de silencio, de soledad y de imaginación, jugaron el juego de los reyes y de los ejércitos en el que las posibilidades se tejen hacia el infinito, en el que las posibilidades se angostan hacia lo concreto sobre un universo en blanco y negro en medio de un fulgor adamantino (Pino 77).

Sí, imposible no imaginarlos jugando esa partida extraña, moviéndose silenciosos con sus mentes exactas, frías y sin sombras en ese universo de espejos y laberintos y libros y apócrifos. Un buen pretexto. 


\section{BIBLIOGRAFÍA}

Aínsa, Fernando. "Las ciudades invisibles de Italo Calvino. ¿Utopía visionaria o crónica de la memoria del futuro?". Borges, Calvino, la literatura (el coloquio en la Isla), Volumen II. Centre de Recherches Latino-Américaines de l'Université de Poitiers (coord.), Madrid, Editorial Fundamento, 1996, pp. 61-84.

Belpoliti, Marco. "El ojo en las ramas". Italo Calvino: Nuevas Visiones. María J. Calvo Montoro y Franco Ricci (coord.), Cuenca, Ediciones de la Universidad de Castilla-La Mancha, 1997, pp. 39-49.

Biasin, Gian Paolo. "Seis hombres con impermeable". Italo Calvino: Nuevas Visiones. María J. Calvo Montoro y Franco Ricci (coord.), Cuenca, Ediciones de la Universidad de Castilla-La Mancha, 1997, pp. 19-29.

Borges, Jorge Luis. "Beppo". Obras Completas, Tomo II (La cifra). Jorge Luis Borges, Barcelona, RBA, 2005, p. 295.

"Prólogo a la primera edición de Historia universal de la infamia". Obras completas, Tomo I. Jorge Luis Borges, Barcelona, RBA, 2005, p. 289.

"El Aleph". Obras Completas, Tomo I (El Aleph). Jorge Luis Borges, Barcelona, RBA, 2005, pp. 617-627.

“Tlön, Uqbar, Orbis Tertius". Obras Completas, Tomo I (El jardín de los senderos que se bifurcan). Jorge Luis Borges, Barcelona, RBA, 2005, pp. 431443.

“Ajedrez”. Obras Completas, Tomo I (El Hacedor). Jorge Luis Borges, Barcelona, RBA, 2005, p. 813.

Calvino, Italo. "El libro, los libros". Diálogos: Artes, Letras, Ciencias humanas 21, №3, 1985, pp. 16-21.

Si una noche de invierno un viajero. Madrid, Siruela, 2006.

Las ciudades invisibles. Madrid, Siruela, 2010.

Calvo Montoro, María J. El problema del lector en la narrativa de Italo Calvino.

Cuenca, Ediciones de la Universidad de Castilla-La Mancha, 1995.

"Umberto Eco, arquitecto: La fundación mítica del 'Edificio' en Il nome della rosa". Relaciones literarias entre Jorge Luis Borges y Umberto Eco. María J. Calvo Montoro y Rocco Capozzi (coord.), Cuenca, Ediciones de la Universidad de Castilla-La Mancha, 1999, pp. 251-277.

CAPOzZI, Rocco. "Cosmicomiche vecchie e nuove: evolución y renovación continuas". Italo Calvino: Nuevas Visiones. María J. Calvo Montoro y Franco Ricci (coord.). Cuenca, Ediciones de la Universidad de Castilla-La Mancha, 1997, pp. 75-87.

Du Plessix Gray, Francine. "Visiting Italo Calvino". The New York Times (web), publicado originalmente en The New York Times, 21 de junio de 1981, sección 7, p 1, consultado el 21 de noviembre de 2021, disponible en: https://www.nytimes.com/1981/06/21/books/ visiting-italo-calvino.html

Gadamer, Hans George. Verdad y método II. Salamanca, Editorial Sígueme, 1998. 
Galli de Ortega, Gloria. "Borges en Italia, Italia en Borges”. Revista de Literaturas Modernas 29, 1999, pp. 161-174.

Genette, Gérard. Palimpsestos, la literatura en segundo grado. Madrid, Taurus, 1989.

Gregori, Lucía. "Combinatoria textual y espacios visuales en Calvino". Italo Calvino:

Nuevas Visiones. María J. Calvo Montoro y Franco Ricci (coord), Cuenca, Ediciones de la Universidad de Castilla-La Mancha, 1997, pp. 51-59.

Hobsbawm, Eric. Historia del siglo XX. Barcelona: Crítica, 2012.

Kristeva, Julia. Semiótica I. Madrid, Editorial Espiral Fundamentos, 1978.

Nietzsche, Friedrich. El nacimiento de la tragedia. Madrid, Editorial Edaf, 2008.

Pino Correa, Juan Carlos. "El juego y el relato". Tiempo de Relatos. Juan Carlos Pino

Correa, Barcelona, Editorial Booket-Planeta, Ámbito Cultural y Gaceta Universitaria, 2008, pp. 75-92.

Poe, Edgar Allan. "El jugador de ajedrez de Maelzel”. Obras completas, Tomo II. Edgar Allan Poe, Madrid, Aguilar, 2005, pp. 85-103.

Scholz, LÁszló. Ensayos sobre la modernidad literaria hispanoamericana. Murcia, Universidad de Murcia, 2000.

Stoka, Tea. "Borges y Calvino: La génesis de la novela Si una noche de invierno un viajero". Verba Hispánica 13, $\mathrm{N}^{\circ} 1,2005$, pp. 79-86.

Van Der linde, Carlos Germán. "Trazos para una estética de la recepción a partir de Si una noche de invierno un viajero". Ensayos. Historia y Teoría del Arte IX, N9, 2004, pp. 183-211.

Weiss, Beno. "Palomar, Calvino y el Pathos de la distancia". Italo Calvino: Nuevas Visiones. María J. Calvo Montoro y Franco Ricci (coord.), Cuenca, Ediciones de la Universidad de Castilla-La Mancha, 1997, pp. 119-133.

Zweig, Stefan. Novela de ajedrez. Barcelona, Acantilado, 2008. 